\title{
LA ESTRUCTURA DEL DOBLE EN EL AMPHITRVO DE PLAUTO Y LA ESTRUCTURA LEXICA VESTITVS-ORNATVS
}

Sosia and Mercurius wear the same dress in the comedy of Amphitruo, but they are not dressed in the same way: Sosia is uestitus and Mercurius is ornatus. The author studies the lexical reasons that can explain these different denominations not as a mere uariatio, but as a lexical opposition, and according to the characteristic structure of the «double».

\section{Introducción}

De todos es conocida la importancia que la comedia de Amphitruo tiene tanto para la literatura latina como para la historia de la literatura en general. La estructura del doble, cuyo exponente más significativo, si no el primero, es precisamente esta comedia, muestra una notable fortuna literaria que, por tan sólo citar dos ejemplos, pasa por la obra de Shakespeare y llega a los horrores del doble y de los espejos que aparecen en Stevenson y en Borges. Volviendo al Amphitruo, voy a mostrar en este trabajo varios argumentos que sugieren la correspondencia entre esta estructura literaria del doble con una estructura léxica que hasta ahora ha pasado desapercibida: la estructura uestio-orno. El objeto de mi estudio se centrará, por tanto, en aquellos textos de la comedia donde aparece uno $u$ otro verbo, o bien sus correspondientes sustantivos uestitus-ornatus, para fijar sus distintos rasgos semánticos y su destribución de acuerdo con éstos. No voy a llevar a cabo, por tanto, ninguna nueva interpretación del Amphitruo, sino tan sólo revisar lo ya conocido desde una nueva perspectiva, la léxica.

La organización del trabajo será la siguiente: en la primera parte haré una breve introducción a la estructura del doble y a la correspondencia de las estructuras literarias con las estructuras léxicas; en la segunda parte, estableceré la estructura uestio-orno en sus precisos términos y, finalmente, en la tercera trataré acerca de su correspondencia con la estructura del doble. 
1. El problema del doble y su importancia

Tan sólo a modo de introducción, es oportuno referir brevemente algunas de las ideas básicas sobre el especial carácter de la obra que estoy tratando, como pieza clave para el estudio de la estructura del doble.

\subsection{Desdoblamiento y planteamiento tragicómico}

El Amphitruo es una obra basada en una serie de desdoblamientos que conforman su estructura y la convierten en una de las piezas más originales de Plauto. Los desdoblamientos pueden clasificarse en estos dos tipos ${ }^{\prime}$ :

a. Desdoblamiento de género: Tragicomoedia ${ }^{2}$

b. Desdoblamiento de personajes: Amphitruo-Iuppiter / Amphitruo // SosiaMercurius / Sosia

Ambos desdoblamientos, a su vez, están en conexión estrecha, pues la conversión de la tragedia en comedia implica, de un lado, el nacimiento de Sosia como el seruus indispensable de toda buena comedia y, por otro, la actuación de Mercurio como seruus de Júpiter en su apariencia terrestre, con el fin de que la pareja humana Amphitruo-Sosia y la pareja divina Iuppiter-Mercurius queden equiparadas ${ }^{3}$.

Esta historia de dobles que es la fábula del Amphitruo presenta, pues, una de las estructuras literarias más afortunadas de la historia de nuestra cultura, que a su vez, y según la opinión de Dupont ${ }^{4}$, tiene también una posible lectura como comedia que trata acerca de la representación y la teatralidad. Estamos, por tanto, en el juego del metateatro $^{5}$ que, entre otros hallazgos, ha dado ser al mito teatral de Sosia-

I Sigo en este punto el artículo de F. Dupont, «Signification théatrale du double dans l'Amphitryon de Plaute», REL 54, 1976, especialmente las páginas 132-135.

${ }^{2}$ Dupont, art. cit., p. 133: "Le point de départ est bien une tragédie (...) Mais une tragédie travestie." Acerca de todos los problemas que conlleva el origen de esta innovación de género y el origen del Amphitruo plautino cf. E. Lefèvre, Maccus uortit Barbare. Vom tragischen Amphitryon zum tragikomischen Amphitruo, Akad. d. Wiss. u. d. Literatur, Mainz-Wiesbaden 1982, pp. 19-33. No es objeto del presente trabajo la discusión de tales consideraciones.

${ }^{3}$ Dupont, art. cit., pp. 133-134.

${ }^{4}$ Dupont, art. cit., p. 131.

s Cf. Barchiesi, «Plauto e il Metateatro Antico», Il Verri 31, 1970, pp. 113-130. 
Mercurio o, en otras palabras, el problema mismo de la identidad, cuya trascendencia literaria no ha podido ser mayor ${ }^{6}$.

\subsection{Estructura literaria y estructura léxica}

Así las cosas, tomando como punto de partida tales premisas, voy a exponer en este trabajo una serie de argumentos que sugieren la existencia de una estructura léxica paralela a la estructura literaria del doble. Las estructuras léxicas, cuando son parejas a las literarias ${ }^{7}$, ponen de manifiesto la sutil y estrecha relación que hay entre la literatura y la lengua, y nos ayudan a entender mejor tanto la una como la otra ${ }^{8}$. Con este trabajo, es mi deseo mostrar que al menos hay una estructura léxica concreta que responde a la estructura literaria del doble. La estructura que propongo parte del hecho de que se empleen términos diferentes para designar las ropas de Mercurio y Sosia, a pesar de que están vestidos exactamente igual. Así pues, Mercurio está ornatus y porta un ornatus, mientras que Sosia se encuentra simplemente uestitus:

$\begin{array}{ll}\text { MERCVRIVS } & \text { SOSIA } \\ \text { ornatus } & \text { uestitus } \\ \text { (vv. 116-119) } & (\mathrm{v} .443)\end{array}$

Este hecho puede interpretarse como una mera uariatio, sin mayor trascendencia, pero también puede haber razones fundadas para explicar la denominación diferente. Creo que la diferencia sémica que tales térmi-

'A este respecto véanse C. O. N. Costa, "The Amphitruo Theme», en T. A. Dorey and D. R. Dubley (edd.), Roman Drama. Critical Essays on Roman Literature, Londres 1965, pp. 87-122; W. Th. Maccary, "The comic significance of travestisms in Plautus, Shakespeare and Beaumarchais», en Letteratura Comparata. Problemi e metodo. Studi in onore di E. Paratore, Bolonia 1981, pp. 293-308; A. C. Romano, "The Amphitryon theme again", Latomus 33, 1974, pp. 874-891, y L. R. Shero, "Alcmena and Amphitryon in ancient and modern drama", TAPhA 89, 1956, pp. 192-238.

7 « $\mathrm{Si}$, por una parte, hay una estrecha relación entre las estructuras gramaticales y las léxicas, por otra parte, no deja de haber una sorprendente correspondencia entre estructuras lingüísticas y literarias» (B. García Hernández, «Proceso aspectual y estructura dramática, Amphitruo de Plauto y Medea de Séneca", en G. Morocho Gayo (Coordinador), Estudios de drama y retórica en Grecia y Roma, León 1987, páginas $218-219$.

${ }^{8}$ Para las estructuras léxicas como entidades capaces de explicar importantes aspectos de la obra literaria o, en su defecto, corroborarlas, véase el trabajo de García Hernández citado en la nota anterior. En F. García Jurado, "Estructuras Léxicas en Plauto", Actas del II Coloquio de estudiantes de Filología Clásica (Valdepeñas 1990), Universidad Abierta, Serie R, n. ${ }^{\circ}$, pp. 253-269, puede encontrarse otra exposición al respecto acompañada de bibliografia reciente sobre el estudio de estructuras concretas. 
nos nos plantean no supone tan sólo una "minucia» de filólogo o una cuestión baladi, sino que más bien está en la médula misma de la estructura del doble que he comentado. A primera vista, puede parecer poco probable que dos verbos tan simples y concretos como uestire y ornare tengan alguna importancia para explicar una estructura que, como la del doble, presenta esa singular relevancia; no obstante, hay un hecho que nos permite pensar en ese sentido, pues sabemos que las metamorfosis de Júpiter y Mercurio no suponen más que un simple cambio de vestido"

\section{Pl., Amph. 866 IV. Amphitruo fio et uestitum immuto meum.}

Basándome en esta idea, voy a proponer la correspondencia de la estructura léxica uestio-orno con la de la propia estructura del Amphitruo. De esta forma, en 2, voy a explicar previamente la estructura léxica uestio-orno en sus términos precisos, y en 3, veremos los pasajes de nuestra comedia que directa o indirectamente están afectados por esta estructura léxica.

\section{La estructura léxica uestio-orno}

Antes de ver cómo se articula la estructura propuesta, consideraré previamente la semántica de orno. El verbo latino orno muestra ya en el latín arcaico una notable variedad de usos que recorren toda una extensa gama significativa, desde el valor de 'preparar' al de 'adornar' (Ernout-Meillet). Presento a continuación un cuadro general de orno, según nos lo ofrece, en términos generales, el $O L D$ de Glare (s.u. orno $)^{10}$ :

Orno $_{1}$ : paro Pl., Cas. 546

$\mathrm{Orno}_{2}$ : instruo Pl., Capt. 447

Orno $_{3}$ : "uestio ut" "Pl., Mil. 790-793

Orno $_{4}$ : decoro, augeo Pl., Epid. 222

${ }^{9}$ Cf. Dupont, art. cit., p. 130: «Dieu dont les métamorphoses ne sont qu'un changement de costume."

${ }^{10}$ Las entradas 5-7 del $O L D$ pueden quedar englobadas en orno $_{4}$, como variantes más específicas con el sentido general de 'adornar'.

"El $O L D$ define este valor en los términos de 'to dress (in a particular costume), atture, rig out' (OLD s.u. orno, tercera acepción). La definición uestio ut que propongo para orno $_{3}$ no supone más que otra manera de expresar el mismo valor, pero más adecuada, en mi opinión, al valor unitario de «intencionalidad» que orno presenta, y del que más adelante trataré. 
Aunque orno presenta esta variedad de valores, es posible hallar un denominador común para todos ellos, que puede explicarse en términos de «intencionalidad», es decir, el hecho de preparar algo con un fin o por alguna razón, como muestra el siguiente ejemplo:

Pl., Truc. 475 sumque ornata $u t$ aegre uidear.

Es, en definitiva, el cometido de ese fin el que va a conferir a orno su valor unitario:

orno, $_{1}$ ' hacer los preparativos para una boda' Pl., Cas. 540

orno: 'proveerse de lo necesario para llevar algo a cabo' Capt. 447

orno $_{3}$ : 'disfrazarse o vestirse para pasar por otra persona' Mil. 790-793.

orno $_{4}$ : 'arreglarse para cautivar a alguien' Epid. 222

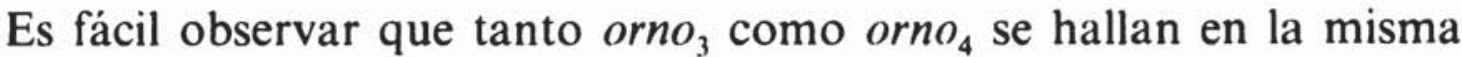
esfera significativa de uestio, pues están referidos al adorno y a la indumentaria, respectivamente. Veamos, pues, cómo se relacionan con este último verbo uno y otro valor de orno. En primer lugar, orno ${ }_{4}$ puede encontrarse en los textos junto a uestio:

Pl., Cas. 768 uestitus, lautus exornatusque ambulat.

Lo mismo ocurre con las formas no verbales correspondientes:

Pl., Epid. 577-578 quia uestitum atque ornatum immutabilem habet haec.

Así pues, la diferencia entre un término y otro, sea una forma verbal o un sustantivo, es clara: uestio indica el hecho de 'estar vestido' y orno $_{4}$ el de 'llevar adornos', diferencia que, por lo demás, nuestra lengua reproduce claramente. En este caso, los objetos designados son distintos, pues uno está referido a la indumentaria y el otro a los adornos, aunque a menudo, en la realidad extralingüística, un vestido pueda ser ya de por si un adorno:

Tert., Pall. 3,7 (uestis inuenta) primum tegendo homini, qua necessitas praecessit, dehinc ornando...

Pero puede plantearse otra relación, si cabe, más estrecha entre uestio y orno. Esta se encuentra en orno $_{3}$, donde este verbo tiene el valor real o figurado de 'vestir(se)', aunque con la especificación 'de una manera especial' $(O L D)$ o, en otras palabras, 'vestirse por alguna razón o con algún fin', noción muy cercana a lo que nosotros entendemos por 
'disfrazarse', que no tiene necesariamente que ver con el hecho de 'adornar(se)' o 'engalanar(se)'. Veamos dos ejemplos ilustrativos al respecto tomados del mismo Plauto:
Pl., Mil. 789-793
PE. habeo eccillam meam clientam, meretricem adulescentulam
Sed quid ea usus est? PA. ut ad te eam iam deducas domum
itaque eam ut ornatam adducas, ex matronarum modo, capite compto, crinis uittasque habeat adsimuletque se tuam esse uxorem; ita praecipiendum est.

En este caso, el personaje femenino al que el texto hace referencia, concretamente una meretriz, no va a aparecer necesariamente más engalanado de lo que lo estaría como tal meretriz, sino vestido de una forma impropia de su condición, pues debe parecerse a una matrona romana. Este valor de orno puede encontrarse igualmente en los sustantivos correspondientes ornatus y ornamentum ${ }^{12}$ :
Pl., As. 68-70 ... qui causa mea
nauclerico ipse ornatu per fallaciam
quam amabam abduxit ab lenone mulierem ${ }^{13}$.

De nuevo encontramos otro personaje, el seruus, que ha tomado un atuendo especial, en este caso el propio de los patronos de barcos, por una razón determinada, que es engañar a un lenón. La relación entre orno $_{3}$ y uestio o de sus respectivos sustantivos se hace todavía más estrecha si pensamos que esos atuendos de matrona o de patrón de barco no son más que unas indumentarias «normales» cuando las toman las personas a las que realmente les corresponden:

\begin{tabular}{|c|c|}
\hline ornatus & uestitus \\
\hline $\begin{array}{l}\text { meretrix ornata ex matrona- } \\
\text { rum modo }\end{array}$ & $\begin{array}{l}\text { - matrona uestita (ex matrona- } \\
\text { rum modo) }\end{array}$ \\
\hline - seruus nauclerico ornatu & 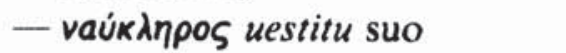 \\
\hline
\end{tabular}

Por tanto, el calificativo de "atuendo especial» es sumamente relativo, pues su aplicación depende por completo de la circunstancia dada y del individuo, en este caso el personaje, que lo adopte. Además, es muy interesante observar que las razones por las que pueden tomarse

12 Ornatus y ornamentum se oponen a los términos respectivos uestitus y uestimentum. Para la diferencia semántica de los sufijos -tu- y -ment-en estos casos véase J. Perrot, Les dérivés latins en -men et -mentum, París 1961, pp. 268-273.

13 Para ejemplos de ornamenta con este mismo sentido véase, por ejemplo, Pl., Capt. 615 y Amph. 85. 
«atuendos especiales» son tan variadas como situaciones presentan las comedias o la propia vida. Pero hay una razón, en concreto, que resulta de una relevancia extraordinaria para nuestro estudio, aquélla que hace tomar un "vestido especial» para la representación escénica, es decir, el vestuario teatral. En este caso, también los atuendos se denominan con el término ornatus u ornamentum. Veamos algunos ejemplos: en los versos finales de Cistelaria, la caterva nos comunica que los actores ya no volverán a aparecer en escena, pues lo que queda por hacer lo consumarán dentro, de manera que, una vez cumplido su cometido, depondrán los trajes de la presentación:

Pl., Cist. 782-784 Ne exspectetis, spectatores, dum illi huc ad uos exeant: nemo exibit, omnes intus conficient negotium. ubi id erit factum, ornamenta ponent.

Todos sabemos, además que el choragus es la persona que proporciona el vestuario escénico, circunstancia que permite a los actores recurrir a él como recurso extrateatral, cuando no saben de dónde van a proveerse de disfraces para llevar a cabo algún tipo de engaño o burla:

Pl., Per. 157-159 (...) TO. et tu gnatam tuam

ornatam adduce lepide in peregrinum modum.

SAT. $\pi \delta \vartheta \varepsilon v$ ornamenta? TO. aps chorago sumito. ${ }^{14}$

Ahora bien, una vez que la representación comienza, los disfraces escénicos pasan a ser, en circunstancias normales, vestidos normales «dentro de la escena», es decir, uestimenta, pues es condición indispensable para que la representación sea verosímil. El uestimentum funciona, pues, como término no marcado en relación a ornamentum:

PI., Amph. 443 itidem habet petasum ac uestitum.

Cur. 415-416 quia uestimenta, ubi obdormiui ebrius, summano.

14 Es significativo que siempre que se hace alguna referencia al vestuario teatral y al corego sean los términos ornatus u ornamenta, sin excepción, los que aparecen:

$\mathrm{Pl}$., Cur. 464 ornamenta quae locaui metuo ut possim recipere.

Trin. 857-858 ut ille me exornauit, ita sum ornatus; argentum hoc facit. ipse ornamenta a chorago haec sumpsit suo periculo.

Así lo señala G. E. Duckworth, The Nature of Roman Comedy, Princeton 1952, p. 89: "Ornamenta, though used of stage properties and of jewelry in particular (cf. Most. 248, 294) refers also (in Plautus) to clothing; the swindler in Trin. $857 \mathrm{f}$. says that the man who hired him to disguise himself "borrowed the costume (ornamenta) from the property man (choragus) at his own risk." Ornamenta and ornatus are both employed in the sense of 'garb', 'attire', but ornamenta regularly occurs when there is mention of the choragus and seems to be the more technical term for theatrical costume.» 
No obstante, todos sabemos que, antes o después de la representación, no son más que ornamenta escénicos, de la misma forma que quienes los portan son, a su vez, actores:

actor sumit ornatum

\begin{tabular}{|c|} 
actor habet uestitum \\
\hline actor agit histrioniam
\end{tabular}
actor ponit ornatum

Con todo, la magia del teatro cobra especial relevancia cuando esos ornamenta continúan siendo ornamenta incluso durante la representación, es decir, cuando lo que se realiza es "teatro dentro del teatro». Voy, pues, a ilustrar este hecho con el ejemplo que considero más significativo, el de Amphitruo ${ }^{15}$.

\section{El par uestio/orno en Amphitruo}

La comedia de Amphitruo nos brinda la oportunidad de estudiar la estructura léxica que propongo en una situación límite, pues, como ya señalé más arriba, Mercurio y Sosia aparecen en la obra portando la misma indumentaria, al igual que Júpiter y Anfitrión. Veamos cómo funciona la estructura léxica de acuerdo con el esquema que seguíamos en 1.1:
a. Desdoblamiento de Género.
b. Desdoblamiento de Personajes.

\section{a. Desdoblamiento de Género}

Voy a comentar varios pasajes del Amphitruo que ponen en evidencia la estrecha correspondencia que ya en la propia lengua puede apreciarse entre el ornatus y la comoedia y, respectivamente, entre el uestitus y la tragoedia $^{16}$. La presencia de bases verbales comunes (miror, muto)

15 A partir de ahora, siempre que haga referencia a orno o a ornatus lo haré siempre con el valor de orno $_{3}$.

${ }_{16}$ Este hecho no tiene nada que ver con las tradicionales clasificaciones de los géneros teatrales latinos (tragoedia, praetexta, palliata, togata...) que, como sabemos, hacen especial referencia al vestuario (cf. A. Pociña Pérez, «Caracterización de los géneros teatrales por los latinos», EMERITA 42, 1974, especialmente pp. $410-415$ y 419 422). La correspondencia circunstancial de ornatus con comoedia que apreciamos en el Amphitruo responde al carácter novedoso y especial que ambos presentan dentro de un contexto de tragedia. 
combinadas con cada par de términos nos proporciona un criterio de comparación bastante fiable.

Dentro del prólogo, Mercurio pide a los espectadores que no se asombren del «atuendo servil» que lleva:

Pl., Amph. 116 nunc ne hunc ornatum uos meum admiremini,

pues resulta extraño que un personaje que afirma ser un dios aparezca en escena vestido como un seruus ${ }^{17}$. De la misma forma, unos versos antes, Mercurio ruega a los espectadores que no se asombren tampoco de que Júpiter vaya a interpretar una comedia:

Pl., Amph. 87-88 ne miremini: / ipse hanc acturus Iuppiter comoediam.

Así pues, tanto el ornatus de Mercurio como la comoedia que Júpiter va a representar aparecen por igual como motivos de asombro debido a su carácter extraordinario, pues en definitiva no son más que las dos caras de una misma moneda:

$$
\begin{array}{l|l}
\text { ne }(\mathrm{ad}) \text { miremini } & \begin{array}{l}
\text { Mercuri ornatum } \\
\text { louis comoediam }
\end{array}
\end{array}
$$

Por otra parte, Júpiter deberá cambiar su indumentaria cuando desee tomar parte en la comedia, al igual que Mercurio. Así podemos verlo en un conocido pasaje de la obra, cuando éste nos refiere que siempre que es su deseo convertirse en Anfitrión cambia sus ropas de dios por la indumentaria humana:

Pl., Amph. 867 Amphitruo fio et uestitum immuto meum.

Podemos considerar en este caso uestitum como término general ${ }^{18}$ ('cambio un vestido por otro': 'cambio de vestido') que engloba las ropas que se dejan (el vestido propio de dios) y las que se toman (el atuendo de Anfitrión) en el lugar de aquéllas ${ }^{19}$ :

uestitum: uestitum ponendum et ornatum sumendum.

${ }^{7}$ Cf. E. Lefévre, op. cit., p. 24.

${ }^{18}$ Un problema de interpretación parecido se plantea dos versos más adelante (868) con el término comoediam. Comoedia puede interpretarse ciertamente en el sentido general de fabula, pero también puede ser considerado en su sentido estricto de 'comedia u obra de género cómico', en oposición, pues, a tragoedia. Cf. E. Lefèvre, pp. 25-26.

${ }^{19}$ Cf. J. Haudry, "L'instrumental et la structure de la phrase simple», BSL 65 , 1970, pp. 62-63: «Lorsque l'échange se fait avec des objets de même dénomination, on a tantôt l'accusatif lat. mutare uestem (...)". 
De esta forma, uestitum aparecería como el término no marcado frente a ornatum, 'el vestido intencionado', al que, a su vez, contendría. En favor de esta interpretación podemos encontrar textos como el de Pl., Epid. 577 uestitum... immutabilem habet haec, donde el vestido aludido hace referencia tanto al que se toma como al que se deja. De igual forma, Pl., Men. 40 immutat nomen auos huic nos da a entender con el término nomen ambas partes del cambio: 'cambiar un nombre por otro', o 'cambiar de nombre'.

La posibilidad de cambiar los atuendos nos permite efectuar una nueva comparación léxica con otro pasaje no menos significativo, aquel en el que Mercurio declara que puede cambiar, asimismo, el género de la obra:

Pl., Amph. 51-53 Post argumentum huius eloquar tragoediae.

Quid contraxistis frontem? quia tragoediam

dixi futuram hanc? deus sum, commutauero.

Precisamente, la base verbal común de immuto y commuto ${ }^{20}$, mutare, nos permite comparar ahora uestitum meum (v. 867) y tragoediam (v. 52) como objetos del cambio, que son sustituidos por ornatus y comoedia, respectivamente. A su vez, podemos apreciar, ahora comparando el desdoblamiento parejo de indumentaria y género, la acción del cambio vista desde la perspectiva del objeto que se toma:

Pl., Amph. 1007 ibo intro, ornatum capiam qui potis decet.

Pl., Amph. 54-55 faciam <iam> ex tragoedia/comoedia ut sit.

De esta forma, la estructura del doble pone en correspondencia uestitus con tragoedia, es decir, la indumentaria y el género teatral propio de Júpiter y Mercurio, y ornatus con comoedia, o el disfraz y el género dramático en que aquéllos aparecen por una cuestión de circunstancia:

IV. immuto uestitum / ME. ornatum capiam

ME. commuto tragoediam / ME. faciam comoedia ut sit

De esta forma, el desdoblamiento de género y de atuendo teatral se presenta en Amphitruo en una estrecha correspondencia que puede apreciarse sin necesidad de salir de la propia lengua; según esto, vemos cómo (ad)miror pone en correspondencia ornatus con comoedia, mientras que immuto y commuto hacen lo propio con uestitus y tragoedia.

${ }^{20}$ Podemos ver combinados ambos modificados preverbiales en Rhet.Her. 4,42. 


\section{b. Desdoblamiento de Personajes}

Como hemos visto, el desdoblamiento del género de la obra es parejo al cambio de indumentaria de Júpiter y Mercurio, que en su faceta trágica aparecen uestiti, mientras que en su faceta cómica están ornati, pues en este caso portan atuendos atípicos de su condición divina; frente a ellos, Sosia siempre estará uestitus, es decir, vestido propiamente como personaje de comedia. Los dos pasajes siguientes son reveladores al respecto; en el primero, Mercurio aparece en el prólogo comentando la peculiaridad de su atuendo, como vimos posteriormente:

Pl., Amph. 116-119 nunc ne hunc ornatum uos meum admiremini, quod ego huc processi cum seruili schema; ueterem atque antiquam rem nouam ad uos proferam propterea ornatus in nouum incessi modum.

Pero, ya en el acto primero, cuando Sosia contempla a su alter ego ${ }^{21}$, sin saber que es un "dios disfrazado", reconoce que, siendo aquél también su persona, lleva ciertamente las ropas que le corresponden, es decir, las suyas (uestitum):

Pl., Amph. 443 itidem habet petasum ac uestitum: $\tan$ consimilest atque ego.

Estamos, pues, ante el ejemplo más notable de la diferencia significativa ente uestio y orno $_{3}$, aquel en el que la misma indumentaria de dos personajes exactamente iguales recibe una denominación diferente, dependiendo de cuál de ellos hable:

$\begin{array}{ll}\text { MERCVRIVS } & \text { SOSIA } \\ \text { ornatus } & \text { uestitus }\end{array}$

La razón, como sabemos, es simple: Mercurio, que ya es un personaje de por sí, realiza dentro de la obra, a su vez, el papel de seruus ${ }^{22}$, propio de otro personaje. Para llevar a cabo esta parodia tiene que ponerse un disfraz teatral (ornatus), que continúa siendo disfraz dentro de la escena, salvo para los ojos de Sosia. De nuevo, el mismo Mercurio vuelve a mencionar su disfraz cuando, por orden de su padre, prepara otra broma pesada, ahora para Anfitrión:

Pl., Amph. 1007 ibo intro, ornatum capiam qui potis decet.

${ }^{21}$ Como es sabido, ésta es una descripción muy interesante por su carácter de anagnórisis cómica (cf. E. Segal, Roman Laughter, Cambridge, Mass., 1968, p. 139).

${ }_{22}$ Cf. D. Guilbert, "Mercure-Sosie dans I'Amphitryon de Plaute. Un rôle de parasite de comédie», LEC 31, 1963, pp. 52-63. Guilbert ha precisado el tipo de seruus que Mercurio encarna en esta comedia según los modelos del servidor galante. 
Merucio vuelve a aparecer ornatus, esta vez ante Anfitrión, que, al igual que su seruus, tampoco podrá reconocer tal ornatus, y creerá que se trata de Sosia:

Pl., Amph. 1024 AM. Sosia!

ME. Ita: sum Sosia, nisi me esse oblitum existimes.

Asi pues, tanto para Sosia, que se reconoce a sí mismo en Mercurio ornatus, como para Anfitrión, que cree ver a su seruus en éste, hay un cómico problema de perspectiva, frente a la omnisciencia de los dioses, y que queda reflejado igualmente en la estructura léxica ornatus-uestitus, pues cada cual va a aplicar un término diferente, según su grado de conocimiento:

MERCVRIVS

- ornatus incedo
SOSIA-AMPHITRVO

- uestitum habet

De esta forma, en los tres textos comentados, precisamente aquellos donde aparece la referencia específica al atuendo de Sosia y Mercurio, la distribución de uestitus y ornatus responde a lo que en un principio esperamos:

MERCVRIVS

vv. 116-119 hunc ornatum

ornatus... incessi

v. 443

v. 1007 ornatum capiam
SOSIA

habet... uestitum

Tampoco debe pasarnos desapercibido el hecho de que estos tres textos objeto de mi comentario aparezcan por igual en lugares muy relevantes del desarrollo de la comedia:

1. vv. 116-119 PRÓLOGO, en boca de Mercurio

2. v. 443 ACTO I, encuentro de Sosia y Mercurio

3. v. 1007 ACTO III, inminente encuentro de Anfitrión y Mercurio

El primero de ellos se inserta dentro del prólogo, en esa especie de «declaración de intenciones» que expone Mercurio ante el público; el segundo nos muestra la visión engañosa que Sosia recibe del dios, y el tercero presenta, ya en la segunda parte de la obra ${ }^{23}$, la disposición de Mercurio para una nueva burla, ahora contra Anfitrión. A todos estos

${ }^{23}$ Para la estructura de la obra cf. W. H. Friedrich, Euripides und Diphilos, Munich 1953, pp. 276-278. 
textos debo añadir el pasaje de Júpiter (v. 866) que vimos más arriba, y de cuya importancia huelga cualquier comentario, tanto para el desarrollo de la comedia ${ }^{24}$ como para nuestro propio estudio (2.1). De esta forma, la estructura léxica uestio-orno hace su acto de presencia a lo largo de toda la comedia, con una especial relevancia para Mercurio, en quien, igualmente, también recae buena parte del protagonismo cómico.

\section{Conclusión}

Hemos visto que una de las realizaciones que presenta el verbo orno es la de 'vestirse de manera especial' o 'con algún propósito', oponiéndose así a uestio, que tan sólo designa el acto no marcado de estar vestido. Las razones por las que alguien puede vestirse de una manera especial son múltiples, pero la que aquí nos interesa es la de representar una obra en escena. El actor, según esto, toma un ornatus, un "atuendo teatral», que, una vez en la representación, pasará a ser el uestitus propio del personaje que se interpreta, como condición indispensable de verosimilitud escénica. Sin embargo, hay ocasiones en que el ornatus sigue viéndose, incluso en escena, como ese disfraz teatral que es en la vida real. En este caso, estamos ante un evidente caso de "teatro dentro del teatro". Así lo vemos en el Amphitruo, donde el dios Mercurio, en calidad de alter ego de Sosia, aparece ornatus, es decir, vestido con un disfraz que no le es propio, mientras que Sosia, aun con las mismas ropas que aquél, está uestitus, pues lleva la indumentaria que le pertenece como seruus de comedia. Sabemos que tanto el ornatus de Mercurio como el uestitus de Sosia son, en realidad, ornamenta escénicos, disfraces para la representación, con la única salvedad de que el de Mercurio continuará viéndose como tal "disfraz» incluso cuando la representación se lleve a cabo, de ahí su denominación como ornatus.

Entiendo, pues, que el análisis de los textos que hacen referencia al carácter del atuendo teatral de Mercurio, Sosia y Júpiter permiten explicar la correspondencia de la conocida estructura del doble en la comedia del Amphitruo con la estructura léxica uestio ('vestir') - orno ('vestir para' o 'de especial manera'). Tal correspondencia puede explicarse se-

${ }^{24} \mathrm{El}$ estudio de un verso clave, como es el 868 de Amphitruo, permite plantear todo el desenlace dramático de la comedia de acuerdo con los verbos inchoare (planteamiento) y transigere (nudo y desenlace), tal y como lo ha mostrado B. Garcia Hernández en su estudio "Plaut., Amph. 867-868. Solución semántica de una cuestión de traducción y de crítica textual», Habis 15, 1984, pp. 117-124. 
gún los dos tipos básicos de desdoblamiento que podemos encontrar en esta obra:

a. Desdoblamiento de Género:

Tragoedia / Comoedia

Vestio / Orno

b. Desdoblamiento de Personajes:

Sosia-Mercurius / Sosia

ornatus / uestitus

De esta forma, lo especial en el Amphitruo resulta ser el ornatus y lo cómico, insertos uno y otro en un tema trágico. Según esto, los dioses, que no sólo intervienen en una comedia, sino que se visten excepcionalmente con las ropas que son propias y normales para un mortal, están ornati, mientras que los personajes humanos aparecen uestiti.

Aunque los textos objeto de mi comentario no son numerosos ( $\mathrm{Pl}$., Amph. 116-119, 443, 866 y 1007), creo que tanto su estratégica posición dentro de la obra como su referencia a distintos personajes los hacen suficientes para explicar la estructura del doble según criterios léxicos. Por lo demás, el resto de las comedias ofrece testimonios completamente acordes con la estructura uestio-orno aquí mostrada. Esta estructura, si bien resulta pareja a la estructura del doble del Amphitruo, va mucho más lejos y se presenta como un reflejo de la teatralidad misma.

Francisco García Jurado 